\title{
Vagueness: A Variant Approach
}

\author{
NiCHOLAS RESCHER
}

Department of Philosophy

University of Pittsburgh

1012 Cathedral of Learning

Pittsburgh PA 15260

U.S.A.

rescher@pitt.edu

\begin{abstract}
Paradoxes of vagueness have been on the agenda since classical antiquity. Some theorists have addressed them by curtailing logical principles (bivalence, excluded middle). Others propose to extrude vagueness as an illusion of sorts rooted overlooking an existing but unidentified boundary or limit. The present paper projects a third prospect, grounded in the idea of a predicative vagrancy, that resolves the issue by epistemological resources via the prospect of ignorance regarding not just the placement but the very existence of a boundary.
\end{abstract}

Résumé: Les paradoxes qui résultent de l'imprécision sont des sujets de discussion depuis l'antiquité. Certains théoriciens les ont abordés en abandonnant certains principes logiques (bivalence, la loi du tiersexlcu). D'autres proposent d'interpréter l'imprécision comme une sorte d'illusion qui nous fait échapper à une limite existante mais non identifiée. On présente une troisième approche, fondée sur l'idée d'errance prédicative, qui résout le problème de ressources épistémologiques par l'entremise de l'ignorance de l'existence et du placement d'une limite.

Keywords: bivalence, boundaries, excluded middle, heap paradox, limits, logical principles, paradox, predictive vagrancy

\section{The sorites paradox and its problems}

Vagueness is a prime source of paradox. For vague terms have a more or less well-defined central core of application, surrounded by a large penumbra of indefiniteness and uncertainty. And since a term $T$ that is vague will automatically have a complement, non- $T$, that is so as well, there will inevitably be a nebulous region of ambivalent overlap between $T$-situations and non- $T$ situations. Here matters seem to stand both ways, so that a paradoxical inconsistency arises.

The most familiar ways of addressing the well-known paradoxes of vagueness call for the use of very heavy machinery, requiring either a

(C) Nicholas Rescher. Informal Logic, Vol. 28, No.4 (2008), pp. 282-294. 
non-standard mode of reasoning (adopting a multi-valued logic, abandoning the Law of Excluded Middle) or a non-standard semantics (abandoning the Principle of Bivalence, accepting truth-value gaps), or both. By contrast, the presently contemplated approach to vagueness proposes to leave the machinery of classical logic and of standard semantics pretty much intact, and to let the burden of paradox-resolution be carried by strictly epistemological considerations. Unavailable information rather than deficient theorizing is here asked to bear the brunt.

The problem of vagueness has a long history. Among the ancient Greeks, Eubulides of Megara (b. ca. 400 BC) was the most prominent and influential member of the Megarian school of dialecticians as whose head he succeeded its founder, Euclid of Megara, a pupil of Socrates.v ${ }^{1}$ Eubulides did more to promote concern for the pardoxicality of vagueness than any other single thinker in the history of the subject. He is credited with seven important paradoxes: The Liar (pseudomenos), The Overlooked Man (dialanthanôn), Electra and her Brother, The Masked Man (egkekalummenos), The Heap (sôritês), The Horns (keratinês), and The Bald Man (phalakros). All of them pivot on issues of vagueness or equivocation.

What here particularly concerns us among these ancient puzzles is the "Paradox of the Heap" - the Sorites Paradox (from the Greek sôros = heap). It is posed in the following account:

A single grain of sand is certainly not a heap. Nor is the addition of a single grain of sand enough to transform a non-heap into a heap: when we have a collection of grains of sand that is not a heap, then adding but one single grain will not create a heap. And so by adding successive grains, moving from 1 to 2 to 3 and so on, we will never arrive at a heap. And yet we know full well that a collection of 1,000,000 grains of sand is a heap, even if not an enormous one. ${ }^{2}$

1 Pretty well all that is known about Eubulides derives from Diogenes Laertius, Lives of the Philosophers, Bk. II, Sections 106-20. See Zeller, Philosophie der Griechen, Vol. II/1, p. 246.

2 On this paradox and its ramifications see Chapter 2 of R.M. Sainsbury, Paradoxes (2nd. ed., Cambridge: Cambridge University Press, 1995), pp. 23-51. Originally the paradox also had a somewhat different form, as follows: Clearly 1 is a small number. And if $n$ is a small number so is $n+$ 1. But this leads straightway to having to say that an obviously large number (say a zillion billion) is a small number. (See Prantl, Geschichte der Logik im Abendlande, Vol. I, p. 54.) Note that the paradox could equally well be developed regressively (i.e., from heapness by substantive 
Throughout the ages, theorists have diagnosed the problem at issue here through locating its difficulty in vagueness, thus affiliating it to a vast panoply of similar puzzles. (Example: a newly-sharpened bread knife is not dull, and cutting a single additional slice of bread with a knife that is not dull will not dull it. Yet when the knife has cut a million slices, it will be dull. Or again: if you are still on time for an appointment, the delay of a nanosecond will not make you late, and yet a great multitude of such delays engenders lateness.) The guiding idea is that in all such cases the pivotal concept—be it "heap" or "bald" or "dull" or "late"—is vague in that there is no sharp and definite cut-off point between the IN and OUT of its application. The "borderline" at issue is not exactly that, but rather a blurred band that is imprecise, nebulous, indefinite, inexact, or some such. And just this is seen as the source of difficulty.

To come to grips with the core to the problem, let $H(n)$ abbreviate the thesis that "A unified collection of $n$ grains of sands is a heap." We can then formalize the premisses of the Sorites paradox as follows:

(1) $\quad \sim H(2)$ (“Two grains do not form a heap.”)

(2) $\quad(\forall n)[\sim H(n) \rightarrow \sim H(n+1)]$ ("If $n$ grains are insufficient to form a heap, then adding just one will not mend matters.")

(3) $\quad H(1,000,000)$ (“A million grains will form a heap.”)

Starting out from premiss (1), repeated application of (2) will yield the negation of (3). So those three premisses are inconsistent. And yet individually considered they all look to be plausible. Hence the paradox. How is it to be resolved?

Since premisses (1) and (3) are uncontestable, it is clearly premiss (2) that will have to bear the burden of doubt. But in rejecting (2) we will, by classical logic's Law of the Excluded Middle, be saddled with its negation, namely:

(4) $(\exists n)[\sim H(n) \& H(n+1)]$

But now if this is accepted, grave problems seem to follow, for by in the widely favored Substitutional Construal of Existential Quantification we will have the principle:

regression) as progressively from non-heapness by additive progression. The former regressive style of reasoning is called Galenic after Galen (AD. 129-c. 210) who wrote prolifically on logic; the latter progressive style Goclenic after Randolph Goclenius (1547-1628) who discussed the matter in his Introduction to Aristotle's Organon. Isagoge in Organon Aristotelis (Frankfurt, 1598). 
(S) If $(\exists x) F x$, then there must be a particular value $x_{0}$ of the variable $x$ for which $F x_{0}$ obtains.

And if this is so, then there will be an identifiable transition-point-a particular and specific integer $N$ for which not-(2) holds good. And so we have:

(5) For some particular, specific integer $N$ there obtains: $\sim H(N) \&$ $H(N+1)$

This upshot appears to be altogether counterintuitive and unacceptable. But nevertheless we seem to have a natural and inevitable transit by standard logic from the rejection of (2) to an acceptance of (4) and thence via (S) to (5). Where does this unpalatable result leave us?

To block this chain of reasoning most theorists have proposed to embargo the move from not-(2) to (4) by some maneuver or other. Mathematical intuitionists propose to accomplish this by prohibiting the move from the refutation of a universal claim to the maintenance of an existential one. Supporters of a "fuzzy" logic propose to abandon the classical laws of excluded middle and tertium non datur.

Against such approaches, however, the present discussion maintains the availability of another, logically far less radical alternative-an alternative to which—so it appear-one must in any case resort on other grounds. This alternative approach pivots on bringing the idea of vagrant predication into operation.

\section{Vagueness as vagrancy}

An important albeit eccentric mode of reference occurs when an item is referred to obliquely in such a way that, as a matter of principle, any and all prospect of its specific identification is precluded. This phenomenon is illustrated by claims to the existence of

- $\quad$ a thing whose identity will never be known.

- an idea that never has or will occur to anybody.

- a person whom everyone has utterly forgotten.

- $\quad$ an occurrence that no-one ever mentions.

- an integer that is never individually specified.

These items are all referentially inaccessible: to indicate them concretely and specifically as bearers of the predicate at issue is straightaway to 
unravel them as so-characterized items. ${ }^{3}$ Yet one cannot but acknowledge that there are such items, notwithstanding the infeasibility of identifying.

The concept of an applicable but nevertheless noninstantiable predicate comes to view at this point. The realizations of such a predicate $F$ will be unavoidably unexemplified. For while it holds in the abstract that this property at issue is indeed exemplified—so that $(\exists u) F u$ will be true - nevertheless the very manner of its specification renders it impossible to specify any particular individual $u_{0}$ such that $F u_{0}$ obtains. Such predicates are "vagrant" in the sense of having no known address or fixed abode. Despite their having applications, these cannot be specifically instanced-they cannot be pinned down and located in a particular spot. So on this basis we may define:

$F$ is a vagrant predicate iff $(\exists u) F u$ is true while nevertheless $F u_{0}$ is false for each and every specifically identified $u_{0}$.

Predicates of this sort will be such that, while general principles show that there indeed are items to which they apply, nevertheless it lies in their very nature that such instances should ever be identified. ${ }^{4}$ It lies in the very make-up of their specification that when $F$ is vagrant, then $F x_{0}$ is a contradiction in terms where $x$ is a specifically identified item-an incoherent, meaningless contention. And this is a very real phenomenon, seeing that such predicates as:

- being a person who has passed into total oblivion

- being a never-formulated question

- being an idea no-one any longer mentions

illustrate this phenomenon. Throughout such cases, specifically identified instantiation stands in direct logical conflict with the characterization at issue. To identify an item instantiating such a predicate is thereby to contradict its very characterization. ${ }^{5}$

We can, of course, refer to such individuals and even to some extent describe them. But what we cannot do is to identify them.

4 A uniquely characterizing description on the order of "the tallest person in the room" will single out a particular individual without specifically identifying him. 
It is this conception of predicative vagrancy that will provide the key to the presently contemplated approach to vagueness. ${ }^{6}$

\section{Vagrancy roots in epistemology}

With vagrant predicates the existence of exemplifications may be an ontological fact, but this is offset by the no less firm epistemological fact that the identification of such exemplifying instance is simply impossible. The impossibility lies not in "being an $F$ " as such, but in "being a concretely instantiated $F$." The problem is not with the indefinite "something is an $F$ " but with the specific "this is an $F$." Difficulty lies not with $F$-hood as such, but with its specific application — not with the ontology of there being an $F$ but with the epistemology of its apprehension in individual cases. Accordingly, vagrant predicates mark a cognitive divide between reality and our knowledge of it.

Now in the abstract and formalistic reasonings of logic or mathematics - where predicates are cast in the language of abstractioncognitive operators of the sort at issue in predicative vagrancy simply have no place. Here one will never encounter vagrant predicates. For in such contexts matters of cognition are never invoked: we affirm what we know but never claim that we know. However, with matters of empirical fact the situation can be very different.

For in those matters of vagrancy that now concern us, cognitive inaccessibility is built into the specification at issue. Here being instantiated stands in direct logical conflict with the characterization at issue, just as with:

- $\quad$ being a sandgrain of which no-one ever took note.

- being a person who has passed into total oblivion.

- being a never-formulated question.

5 To be sure one could (truthfully) say something like "The individual who prepared Caesar's breakfast on the fatal Ides of March is now totally unknown.” But the person at issue here goes altogether unknown, that is, he or she is alluded to but not specified-individuated but not concretely identified. So I cannot appropriately claim to know who the individual at issue is but only at best that a certain individual is at issue.

6 For Further details regarding such vagrancy see the author's Epistemic Logic (Pittsburgh: University of Pittsburgh Press, 2005). 
- $\quad$ being an idea no-one any longer mentions.

To identify an item of this sort is thereby to unravel its specifying characterization.

The difference between predicate vagrancy and its contrary mirrors the contrast between:

- generic knowledge: it is known that something has: $\mathcal{K}(\exists x) F x$.

and

- specific knowledge: something that has $F$ is know about, that is, one knows of something in specific that it has $F:(\exists x) \mathcal{K F}$.

Here $\mathcal{K}$ can be read either as the impersonal "It is known that" or alternatively as the egocentric "I know that".

In the former case it is merely known that $F$ has application, in the latter case one is in a position to identify a specific example of $F$ application - to adduce a known instance of $F$. From the logical standpoint, then, the issue comes down to the relative placement of the existential quantifier and the cognitive operator.

\section{A vagrancy approach to vagueness}

And now back to vagueness. Wherever it functions, there is no viable way of separating the INs from the OUTs. But here one can take either an ontological or an epistemic approach. The former effectively says "there is no definite boundary" the latter says "there indeed is a definite boundary but there is no practicable way of locating it, no feasible way of noting where it lies." The one denies the existence of boundaries, the other their identifiability.

In the case of the heap paradox these opposites afford two possibilities. The one consists in flat-out denying the thesis:

$$
(\exists n)[\sim H(n) \& H(n+1)]
$$

But yet another alternative approach proceeds by retaining this contention but blocking the move from it to:

There is a particular, determinable value $N$ of the variable $n$ for which the preceding contention holds.

In effect we now bring the concept of vagrant predicates to bear. For by treating vagueness as vagrancy we effectively block the Heap Paradox 
and its congeners. For once that pivotal predicate which characterizes a transition from non-heap to heap is seen as vagrant, the whole idea of locating that problematic transition value vanishes from the scene. The two conceptions-vagueness and vagrancy-can thus be seen as functionally symbiotic.

To be sure, an approach to vagueness along these lines involves a non-standard handling of the issue of a transition point between the INs and the OUTs. For the traditional approach to such boundaries is that of the ontological contention that they do not exist as such (i.e., as actual boundaries), but are to be replaced by penumbral regions (whose boundaries themselves are penumbral in turn-all the way through). And this means that there will fail to be a "fact of the matter" in regard to being IN or being OUT, so that the logical principle of Tertium non dattur has to be abandoned.

With vagueness there will be a region of indeterminacy as between the INs and the OUTs, but that this region is, as it were, penumbral. It will not itself have sharp, razor-edged boundaries but must be nebulous, with the boundary between IN and INDETERMINATE (and again between INDETERMINATE and OUT) will itself be comparably indeterminate (penumbral, "fuzzy") once more. The absence of clear transitional borders will hold "all the way through" so to speak.) For this reason, a three valued logic of TRUE, FALSE and INDETERMINATE will not do the job that is needed here. Any "fuzzy logic" adequate to the taste of accommodating vagueness must be infinite-valued, with neverending room for shades and gradations. Pretty complex logical machinery needs to be brought to bear.

By contrast, our present vagrancy-based approach takes an epistemological line. It does not call for denying that there is such a thing as a (classically conceived) boundary. And it does not deny that any given item either is IN or not. In sum it does not conflict with the idea that facts are at issue here. But what it does insist upon is that these facts are in principle undeterminable. For the predicate

\section{being the boundary between IN and OUT}

is now classed as vagrant. The correlative shift from ontology to epistemology leaves traditional logic pretty much intact.

The vagrancy-based approach to vagueness pivots on the critical distinction between the located and the locatable. As it views the matters, there indeed is (ontologically, so to speak) a sharp and clear boundary between the INs and the OUTs, but that there is (epistemically, so to speak) no possible way of locating it. In taking this line, the recourse to predicative vagueness shifts the burden from the ontological to the epistemological side of things. The advantage of such a strategy is that it makes it possible to keep in place a classically binary logic and foregoes abandoning the classical principles of excluded middle and tertium non 
datur. The only innovation needed —and one that will be required in any case-is to accept the prospect of vagrant predication.

What we have here is the anomaly of a boundary (as between being a heap and a non-heap, a sharp or dull knife, a same-color patch and a different-color patch) representing an IN/OUT demarcation that is inherently invisible. Such a boundary exists—so it is held—but remains inherently unidentifiable. Viewed from this perspective, vagueness emerges as a product of insufficient cognition. The indefiniteness at issue is now ascribed not to reality's indecisiveness, but rather to that of our epistemically problematic concepts—as reflected in the indefiniteness of vagrant predicates.

And so, while the standard view of vagueness sees the separation of vaguely bounded regions as a matter of unlimitedness-the result of definite boundaries - the present nonstandard approach combines an insistence on the existence of boundaries with an insistence on their (epistemic) unlocatability. The positions are very different but there net effect is in one respect the same: no specifiable boundaries.

\section{Further perspectives}

There is a multitude of examples of objects that are real but unidentifiable. As regards the future, the person who will win the 2020 U.S. presidential election is for-sure currently alive and active among us, but cannot yet possibly be identified. And as regards abstractions there must exist an unprovable arithmetical theorem whose Gödel number is the lowest-but this too cannot possibly be identified. Our present treatment of vagueness extends this actual—but unidentifiableapproach tot hose otherwise nebulous boundaries involved with vagueness.

After all, one must avoid equating nonspecificabiltiy with nonexistence. For as we have seen time and again, vagrant predicates, though uninstantiable by us, need not in themselves be uninstantiated. There will certainly be (some) totally forgotten people, though none of us can possibly provide an example. And analogously, it could be held that there indeed is a sharp boundary between heaps and non-heaps (of sandgrains of a given size) even though it is in principle impossible ever to say just where this boundary lies. It is concealed in a cognitive blindspot, as it were. ${ }^{7}$ For while-from such a perspective, these indeed is a transition, and even a transition-point, nevertheless this is not something that can possibly be fixed upon and identified.

Consider, for example, a color strip of distinct compartments as per:

7 For further, different cases of this general sort see Roy E. Sorensen, Blindspots (Oxford: Clarendon Press, 1988. 


\begin{tabular}{|l|l|l|l|l|l|l|l|}
\hline $\mathrm{C}_{1}$ & $\mathrm{C}_{2}$ & $\mathrm{C}_{3}$ & $\mathrm{C}_{4}$ & & & & \\
\hline
\end{tabular}

where adjacent compartments are visually indistinguishable in point of phenomenal color:

$$
(\forall i)\left[P\left(c_{\mathrm{i}}\right)=P\left(c_{\mathrm{i}}+1\right)\right]
$$

Nevertheless, the situation is such that there will be notable differences among sufficiently remote compartments. Thus we will have:

$$
P\left(c_{1}\right) \neq P\left(c_{100}\right)
$$

But where is one to place the transition between $P\left(c_{\mathrm{i}}\right)$ and $P\left(c_{100}\right)$ ? Where does $P\left(c_{\mathrm{i}}\right)$ end the where does $P\left(c_{100}\right)$ begin? Here we have exactly the same problem as with heaps. And exactly the same sort of solution looms before us with a resort to predicative vagrancy able to do the needed work. ${ }^{8}$

Now on the present epistemic perspective, the crux of vagueness is that while one knows that there is a transition point between IN and OUT, nevertheless one cannot possibly manage to locate it. And just this represents a fundamental aspect of vagueness in general: there just is no way of saying at just what point predicate-applicative begins and where it ends. We know that a cross-over is eventually reached, but cannot possibly say just where it lies.

\section{The epistemological turn}

Such treatment of vagueness takes the line that there indeed is a boundary between the INs and the OUTs in matter of vagueness, so that one can maintain:

(I) $\quad(\exists B)[B$ marks the boundary between IN and OUT $]$

Nevertheless, there is no way of fixing this boundary, no way of determining just exactly where it lies. There is no prospect of identifying a particular value of $B_{0}$ of the variable $B$ such that

(II) $B_{0}$ marks the boundary between IN and OUT.

8 This shows that transitional continuity is not the core of the problem: the selfsame situation can confront us in the discrete case. 
From the ontological/existential point of view the existence of a boundary is acknowledged as per (I). But from an epistemological/cognitive point of view any and all possibility of locating this boundary — of determining or specifying it—is precluded.

Exactly this is the characteristic situation of predicative vagrancy. As adumbrated above, the crucial difference here is the that between the acceptable indefiniteness of:

$\mathcal{K}(\exists B)$ ( $B$ mark the boundary between IN and OUT)

and the unacceptable:

( $\exists B) \mathcal{K}(B$ mark the boundary between IN and OUT)

And in viewing the matter as one of vagueness, the existence of a boundary point is conceded, but any and all prospect of its specifiability is denied.

So viewed, the ultimate responsibility for the indefiniteness of vagueness thus lies not with what is at issue in our discourse, but rather in the imperfection of our knowledge: "the fault is not in our stars, but in ourselves" in that our very vocabulary precludes exact knowledge by being indefiniteness-friendly.

The crux of such an approach to vagueness is that the descriptive qualifier "is a transition point between IN and OUT" is to be seen as a vagrant predicate-it applies someplace, but we know not where: items may well fall into the indeterminate "jut can't say" region. (The boundaries of that indeterminate region will themselves be specified by vagrant predicates.) In principle undecidable propositions occur not just in mathematics but in the factual domain as well.

But just what is the pay-off difference between saying that there just is no boundary and saying that there is one but it is altogether unidentifiable? Simply and exactly the difference between the epistemic and the existential. It is one thing to say that there is nothing in the box and quite another to say that there is no way for anyone to know what it contains. (Think of the magic box-impenetrable to external scanningwhose content is annihilated by opening the lid.)

\section{Ramifications}

Our claims regarding reality generally fall short in point of accuracy and detail for reasons ultimately rooted in our human condition as beings whose knowledge is mediated by language. A descriptive term is equivocal when its application invites the question: "In what sense?" (Example: gay or crooked). A descriptive term is vague when its application invites the question: "Of what sort or kind?" (Example: 
vehicle or metal.) A descriptive term is ambiguous when its application invites the question: “In what mode, respect, or manner?" (Example: instructive or incompetent.) A terms is inexact or imprecise when its application invites the question: "In what degree or to what extent?" (Example: large or old.) Moreover, a descriptive terms is figurative when it is in some respect metaphorical or analogical, so as to invite the question "just how is this so?" As such cases indicate, human communication is replete with unclarity and inexactness, ever admitting further questions about the purport or what has been said. While reality itself is interrogatively complete, our thought and discourse about it certainly is not: We are constantly constrained to use loose terminology and fill our discourse with expressions on the order of "roughly," "approximately," "something like," "in the neighborhood of," "in his 70s," "some six feet tall," and so on. This prominence in our discussions of indecisiveness — of vagueness, equivocation, and the rest-has larger ramifications.

Consider, for example, dealing with an inscription that reads:

\section{$\mathrm{R} \mathbf{\mathrm { T }}$}

We just cannot make that middle letter out. On the basis of the general principles of the English-language setting we can maintain:

(1) must be a vowel

(2) Only A, O, U are real possibilities

Of course if we had some context we could go further, as per:

- He was bitten by a RaT

- He left it in the street to R $\mathbf{m}$

- He got stuck in a RaT

Context often will, or at least can, pave a way to determination here. But in the absence of a context all we can say is

(1) We know that the missing letter is one of A, O, U:

$$
K(\mathbf{\square}=A \vee \mathbf{\square}=O \vee \mathbf{\square}=U)
$$

(2) But we do not know which of them in particular it is:

$$
\sim K(\mathbf{\square}=A) \& \sim K(\mathbf{\square}=0) \& \sim K(\mathbf{\square}=U)
$$


In sum, what we have here is the typical vagrancy situation of

$$
K(\exists x)(\boldsymbol{\square}=x) \& \sim(\exists x) K(\boldsymbol{\square}=x)
$$

We know that $\mathbf{\square}$ is one of $\mathrm{A}, \mathrm{O}, \mathrm{U}$., but have no clue as to $\mathrm{i}$ of this trio that problematic actually is. It is clear on this basis the predicate

being the letter represented by

is (contextually) vagrant.

And so with equivocation too we have a situation that can be analyzed in terms of predicative vagrancy. And the situation of vagueness can be seen as simply a more ordered version of this same phenomena. In effect, both vagueness and equivocation can be seen as yet another mode of unknowability.

\section{Why vagueness pays}

The fact of it is that reality is so vastly complex in its mode of operation that a shortfall of detail in our description of it is an inevitable reality. In characterizing the real in man's natural language the indecisiveness of vagueness is not a failing but an inevitability. And so, one reason for our tolerance of congenerers lies in our having little choice about it.

All the same, its vagueness does not stop a statement from being true. If we could not describe the grass of our experience as vaguely green or indeed even merely greenish, but only had the choice of a myriad exact shades of green, color communication would virtually grind to a halt. If we had to decide when "rock" leaves off and "boulder" begins, we would be in difficulty. Despite its manifest problems, vagueness is immensely useful simply because precision is too hard to come by and deploy.

And so in the final analysis we tolerate vagueness because we have no choice, and we do so gladly not just because it is convenient, but also because greater detail is generally not needed in the relevant contexts of operation. (We do not need to know whether the approaching storm will bring 1 or 1.5 inches of rain for deciding whether or not to take an umbrella.) $)^{9}$

9 Further information on paradoxes can be found in the author's Paradoxes (Chicago: Open Court, 2001). An extensive literature cited there, including: J. C. Beall, (ed.), Liars and Heaps: New Essays on Paradox (Oxford: Clarendon Press, 2003); L. Burns, Vagueness: An Investigation into Natural Languages and the Sorites Paradox (Dordrecht: Reidel, 1991); V. McGee, Truth, Vagueness, and Paradox (Indianapolis: Hackett, 1990); R. M. Sainsbury, Paradoxes $2^{\text {nd }}$ ed. (Cambridge: Cambridge University Press, 1995) [see especially Chapter 2, "Vagueness: The Paradox of the Heap”]. 